\title{
EFL Flipped-Classroom: Promoting HOTS in Speaking Skill
}

\author{
Zahratul Riza, Sri Setyarini \\ English Education Department, School of Postgraduate Studies \\ Universitas Pendidikan Indonesia \\ Bandung, Indonesia \\ zahratulriza@upi.edu
}

\begin{abstract}
Flipped-classroom has been reported to be able to provide more exposure as well as more opportunity to develop students' higher-order thinking skills both inside and outside the classroom. However, this pedagogical model is generally implemented at the university level instead of the secondary one. o fill $t$ gap, the present study aims at investigating the development of HOTS promoted through speaking activities among secondary school students in EFL flipped classrooms. This case study gathers data from classroom observations, interviews with the teacher, and analyses of teacher's lesson plans, assessment and uploaded video lectures. The finding of the study reveals that the flipped classroom conducted by Acehnese EFL teacher is in line with the EFL flipped-classroom framework developed by the experts theoretically. Meanwhile, practically, it also can offer the occasion for students to stimulate their HOTS while engaging in activities.
\end{abstract}

Keywords: flipped-classroom, higher-order thinking skills (HOTS), m-learning, speaking skill

\section{INTRODUCTION}

Most students are often not exposed to the language in the environment and have little chance to practice or speak English while studying in traditional EFL classroom (Yu, 2019). This kind of condition may fail EFL teaching which leads to the weak achievement of English proficiency, particularly speaking skill as one of the ultimate goals in learning English. In such a situation, the flipped-classroom pedagogical model is one of the alternatives implemented as the effort to ensure students get more exposure and much time to practice the language ( $\mathrm{Li} \&$ Suwanthep, 2017). A flipped classroom is often defined as the inverted classroom in which the lecture content is learned at home in the form of videolecture while the homework or task is done at school (Bergmann \& Sams, 2012; Chuang, Weng, \& Chen, 2018; Zainuddin, Habiburrahim, Muluk, \& Keumala, 2019).

On the other hand, this innovative pedagogy tries to change the way teachers taught by converting what traditionally occurs both in and out of the classroom (Jacob, \& Matthew, 2013; Zainuddin et al., 2019). Unlike other conservative classrooms where the teacher becomes the Sage of the Stage in a lecture-based class, the flipped classroom allows the teacher to be the Guide on the Side in an activitybased class allowing students to be more active and interactive. Bergmann \& Sams (2013) argued that the increase in student-centered active learning time in the flipped classroom can lead students to have more opportunities to activate input, output, and interaction practices during the learning.

Similarly, Zainuddin et al. (2019) stated that flippedclassrooms with the employment of a video-recorded lecture uploaded in a certain learning management system (LMS) provides more time for students to interact with peers and teachers both inside and outside the classroom. Furthermore, Lo and Hew (2017) declared that the flipped classroom can also develop all levels of students' cognitive process dimensions based on revised Bloom's Taxonomy. It is in line with the statement from Bergmann and Sams (2012) that say that flipped classroom model can cover 6 cognitive domains of thinking wherein Lower-Order Thinking Skills (remembering, understanding, \& applying) are accomplished outside the class session while Higher-Order Thinking Skills (analyzing, evaluating, \& creating) are treated inside the classroom. Thus, flipped classroom allows students to have more exposure toward the language both online and offline, which can assist them to get ready for speaking activities while developing their higher-order thinking skills. Relating to the EFL context, to engage students in meaningful speaking activities as the endeavor to develop their higher-order thinking skills, the flipped classroom can be an alternative way for students to prepare themselves well before participating in the speaking activity given before the class. Based on the discussion above, a theoretical framework of EFL flipped-classroom to foster HOTS as adapted from Alsowat (2016) is shown below (See Figure 1).

Various studies reported the implementation of the flipped classroom and its integration into students' speaking skill or oral competence, English language higher-order thinking skills, and self-efficacy skills (Alsowat, 2016; Li \& Suwanthep, 2017; Lin \& Hwang, 2018; Quyen \& Loi, 2018, Zainuddin et al., 2019). The study conducted by Lee and Wallace (2018) found that the flipped classroom model allows students to have more time in practicing English wherever they are. Recently, a study in Taiwan indicated that online community-based flipped classroom is very influential in improving the oral presentation of university students through the utilization of Facebook (Lin \& Hwang, 2018). 


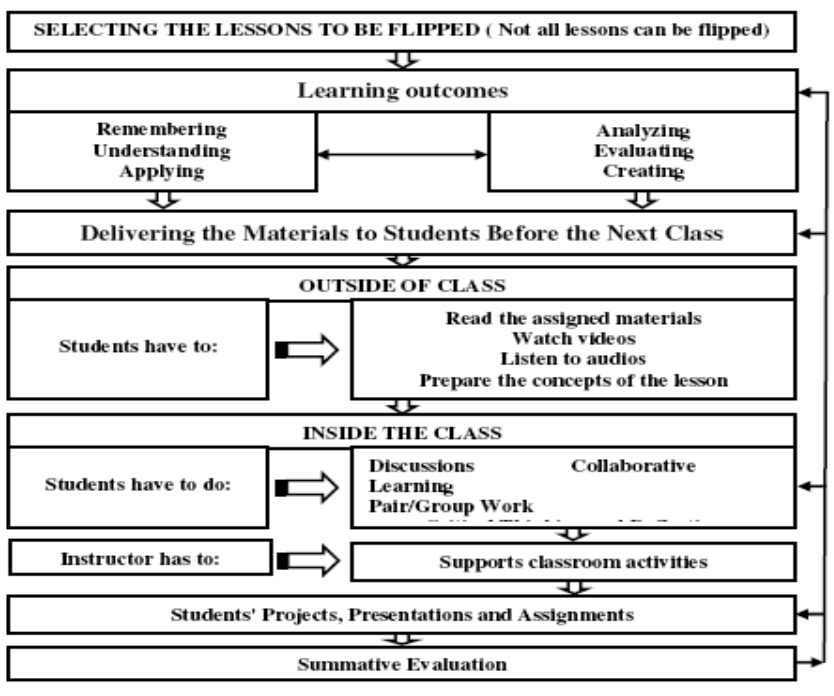

Fig 1. The Theoretical Framework of EFL Flipped-Classroom

Besides, the implementation of EFL flipped classroom and the utilization of video lectures as well as LMS can allow students in higher education to be self-regulated learners and to interact and communicate more with peers and teachers especially in speaking class as reported by Zainuddin et al. (2019). Li and Suwanthep (2017) also found that there is a positive effect of the flipped-classroom model for EFL speaking in their quasi-experimental research at a University in Thailand. Furthermore, Quyen and Loi (2018) examined the potential of integrating the flipped model to improve university students' speaking performance in Vietnam. The findings of this research showed that the students in the experimental group achieved higher scores in speaking tests than those in the control group.

Additionally, there is also research about the impact of flipped-classroom implementation toward the English language Higher-Order Thinking Skills, students' engagement and satisfaction conducted at a University in Saudi Arabia (Alsowat, 2016). Nevertheless, the last one is conducted quantitatively and did not focus deeply on HOTS in speaking skills.

As fairly little research has been conducted on how the implementation of the flipped classroom at secondary school develop EFL students' HOTS in speaking skill, the objective of this study is to investigate how flipped-classroom pedagogical model can promote the Higher-Order Thinking Skills of rural area students while engaging in speaking activities and also figure out the challenges encountered by the EFL teacher to reach the learning outcomes.

\section{METHOD}

This research was a case study that examined the application of flipped-classroom in promoting students to develop their HOTS while speaking as well as challenges that emerged in a small flipped-class size through the qualitative lens (Creswell, 2012). The site of the study was a senior high school located in a rural area in Indonesia in which 1 EFL teacher and 28 students (grade 11) were recruited as participants by using purposive sampling. Data were garnered from classroom observations, document analysis and a semi-structured interview with the teacher.

\section{FINDINGS AND DISCUSSION}

Based on the classroom observation and the interview with the teacher, the two research questions are answered. First, it is found out that there are 3 phases of flipped classroom suggested by Bergmann and Sams (2012) that had been implemented by the teacher in flipping her English speaking classroom namely: 1) pre-class activity, 2) in-class activity, and 3) after-class activity. The teacher conducted this flipped-class under the topic asking for and giving an opinion for two meetings. The pre-class activity is done by the utilization of WhatsApp application for about 2 days before the face-to-face class whilst the face-to-face meeting in the second stage lasted ninety minutes each. Here are some steps recorded by the authors,

\section{First meeting:}

In the first phase (pre-class activity), the teacher firstly delivered learning materials in the form of video and digital modules through the WhatsApp group. The videos uploaded were taken from YouTube discussed the expressions of opinion, while the digital module shared was created by the teacher herself. Besides, the teacher also shared a teacher-made online quiz relating to the materials. Secondly, the students watched a video and read the module. Then, the teacher instructed students to do the quiz consisted of LOTS questions. After that, students were given free-time to ask, comment, and discuss the materials. The discussion is mostly done in English and a little bit in Indonesian. During this online discussion, the teacher came with feedbacks that encourage students to develop their remembering, understanding and applying skills related to the materials being learned.

In the second phase (in-class activity), the teacher started the class with a review section in which the teacher asked the students to retell what they have watched and learned previously at home. She also checked the students' understanding of the materials by giving them some oral quiz as well as supported them to use some giving opinion expressions.

Afterward, the teacher had the students played "a life-boat" game. They were divided into 6 groups with 6 different professions (Teacher, Pregnant woman, Fisherman, Army, Doctor, and President) and asked to defend themselves for not being thrown out of the boat by giving some reasons why they should stay in the boat and why the other professions should be kicked out of the boat. Here, they were also asked to evaluate the reason or opinion of other students in reaction to "do you agree with him? why? or why don't you agree? State your opinion". Some were able to apply or practice the expressions without thinking anymore while some were still confused about which expressions to use when the teacher changing the situations. Interestingly, several students were very good at analyzing and evaluating the information they heard as well as creating new sentences. For example, one student stated, 
In my opinion, the Army should leave the boat since he had been traineded to swim well during military training.

Another student also mentioned,

In my point of view, the teacher is one of the professions that should be kept in the boat because in my case as the teacher, I do not know how to swim. If kicked out from the boat, I think I might die. And if I die, the country will have died too because there will be no one can teach and create the next best generation for the country.

Meanwhile, the other student said,

As the president, I think I should be thrown up into the ocean to save my people's life.

Furthermore, in the third phase (after-class activity), the teacher facilitated students to reflect their learning and practice the expression of asking for and giving opinions in their reallife with their peers. They were also encouraged to continue using those expressions in the WhatsApp group in which the teacher provided another topic to learn and discuss for the next meeting.

\section{Second Meeting:}

In the pre-class stage, students were given 1 news article regarding the enjoinment of PUBG in Aceh province and 1 video regarding this issue through the WhatsApp group. They were instructed to read the articles, learn the vocabulary provided related to the text, and answer some LOTS questions following the articles. Then, the students discussed the answers in the WhatsApp group while the teacher provided them some feedbacks and several motivational words.

In the in-class stage, the teacher reviewed and checked students' understanding just as she did in the first meeting. Asking them LOTS and HOTS questions about the issue as well as helped them to recall some expressions in giving an opinion. Then, the teacher instructed students to sit in pairs, read a picture, and state their opinion toward the pictures shown by the teacher. The pictures were about the negative side of the PUBG game. This kind of activity was aimed to remind the students to practice the expression of opinion as well as enhance their HOTS level (Analyzing, evaluating, and creating). For example, one student said,

To my mind, this picture tells us the bad effects of PUBG if we keep playing it all the time. First, we will sit in front of the computer or our phone till we forget about the studying time and forget about praying too. Second, it brings a bad effect on our health. Watching the phone's screen will damage our eyes, our brain, and expose us to dangerous radiation from the electricity.

Besides, in response to the question do you think PUBG will ruin your school life if you play it? Another student said,
No, it will not ruin my school life. I believe playing PUBG is addictive. Nevertheless, when I play it at my home, I first set my time to remind me to study. So, I think my school life will be okay and hopefully, this game should not be banned in Aceh.

Furthermore, the students were divided into two groups in which one group acted as the affirmative and the other was the negative team. Another team was allowed to comment on or ask the opposite team's argument. Unfortunately, no team wanted to argue other's opinions.

In the after-class stage, the teacher keeps facilitating and motivating students to have an oral discussion by using the expressions of asking for and giving opinion in the real-life and the WhatsApp group with any different topics related to students' interest.

From the aforementioned activity, the majority of students were recorded to be able to use some expressions of opinion such as I think, I feel, I believe, in my opinion, to my mind, according to me, and so on. Some of them also showed the development of analyzing certain conditions, evaluating it, and creating creative answers or new sentences based on the vocabulary and language pattern they have learned or based on the information they got from various sources. Another important thing that should be taken into account based on this classroom observation is the teacher was in the same path as the theoretical framework adapted from Alsowat (2016) in conducting EFL flipped-classroom to develop students' higherorder thinking skills while engaging in speaking activities like role-playing, discussion, pair/group work, debate, etc.

Second, the implementation of flipped-classroom in teaching speaking is relatively new to the teacher in this rural area. However, the teacher's efforts to conduct HOTS-based teaching should be taken into account. The fact that pre-class activities allow students to prepare themselves to face the inclass activities demanding them to speak and responds to HOTS-based questions, shows that flipped-classroom can help them to decrease their anxiety to speak in English and develop their cognitive thinking levels during speaking as well.

Nevertheless, the teacher still encountered some challenges in implementing the flipped-classroom model to promote HOTS in speaking skills. Based on the interview, the challenges include teacher's limited skills and resources in creating the appropriate online video lecture $\&$ designing online formative assessment, students' limited learning tools/media, students' lack of vocabulary, students' speaking anxiety, students' limited English proficiency, students, and lack of motivation to engage in the pre-class online discussion. In response to the question "what are the challenges you encounter during teaching English through the flipped classroom model?". The teacher said,

There are some problems while flipping this English classroom. First, I made is inaccessible to my students' phone. It was reported to be an unsupported application on their gadget. I think I need to purchase, find, or learn to use other easy-to-access application programs to 
assure students can easily access their teacher's madevideo lecture and assessment. Second, only 18 out of 28 students can access online materials and join the learning platform whilst the rest cannot.

In addition, towards the question "why did you use WhatsApp as the learning platform?". The teacher replied,

Basically, I intended to utilize "Rumah Belajar" as the learning platform for this English flipped-classroom to help me record their online activity, but my students' found it a way more difficult to access it through their phone. This was the reason why we ended up using WhatsApp group to connect us in the pre-class session.

Further, when it comes to "what challenges did you face while trying to develop higher-order thinking skills of students in speaking?. The teacher stated,

[I]nstructing students to foster their speaking skill as well as HOTS is challenging for me since most of my students were lack of confidence to speak, and also lack of vocabulary to express ideas. So, I familiarize certain vocabularies in the pre-class activity. However, it is inaccessible for some students due to technical reason which resulting them to learn LOTS level materials in the in-class activity.

Besides the limited learning tool, limited English proficiency, and lack of vocabulary, students' motivation to engage in the forum is also being the challenge. As the teacher said,

Another problem is that few students (not to mention those who did not join the group) still hesitated to involve in the online WhatsApp group discussion. It probably happened because they were required to use English during texting or recording their voice. Thus, I asked them to feel free to use mixed-language hoping that they will be more active in the online discussion which will lead them to be more active in the speaking activity that I had prepared for them to be engaged in the classroom later.

To guarantee that this flipped-classroom model can promote HOTS while engaging in speaking activity, there were some documents analyzed in this study namely the teacher's lesson plan, teacher's made the assessment, and uploaded video lecture. Lesson plans prepared by the teacher show that the teacher has designed the activity (opening, main activity, \& closing) that can cover all six cognitive domains of Bloom's revised taxonomy (Anderson \& Kratwohl, 2000).

In addition, the lesson plans also show some HOTSbased questions. Students were not only asked to recall the information and review their understanding of some expressions of giving or asking for the opinion that they have watched before class through the video but also to apply it by using this expression when responding to teacher's sudden quiz in class such as what is your opinion about his new bag or why do you agree with her view and so forth. Some questions that start with how, what if, and if you, for example, if you were the teacher, why do you think you should stay in this boat? or if you were the parents, will you allow your children to play PUBG? Why? also demanded students to develop the remaining levels of HOTS (Analyzing, evaluating, and creating).

Similarly, the teacher's made assessment in the form of online quiz is analyzed as well. Since it aimed to recheck students' understanding of the materials given in pre-class activity, it contains of LOTS questions in the form of multiple choices. Following those LOTS questions, the teacher had prepared some HOTS questions to be asked in the classroom such as do you agree that PUBG should be banned? State your opinion, how will you protect yourself from being addicted to PUBG? or what will happen is PUBG still accessible in our country and so forth

Afterward, in this EFL flipped-classroom, the teacher shared some video lectures. For the first meeting, there are 3 videos in English regarding the expression of asking for and giving an opinion. Meanwhile, for the second meeting, the teacher merely shared 1 video in Bahasa Indonesia and 1 news article informing about the banning of players' Unknown Battleground Game (PUBG) in Aceh. Each video was 3 to 4 minutes in length. The videos were informative and interactive in which the students can get more exposure toward English and its word pronouncing. Besides, the teacher also supported students with supplementary materials in the form of digital modules made by the teacher, pictures related to the materials, and some links to find out more about the materials being learned. The contents of the videos were filled with a lot of factual and conceptual knowledge as the gate for students to foster their HOTS level through the HOTS-based activity in the classroom.

\section{CONCLUSION}

Based on the results, this study concludes some important points. First, rural area school can apply the flipped classroom pedagogical model. Second, the teacher's competency in designing various speaking activities and providing HOTSbased questions contributes a lot in stimulating students' HOTS while speaking. Thus, teachers should develop their professional and pedagogical competency, including the ability to create HOTS-based questions and conduct HOTS-based teaching practice. Third, the flipped-classroom is probably one of the best alternatives to have well-prepared students in teaching speaking skill. Fourth, the flipped-classroom has inverted teacher-centered learning to student-centered. Fifth, this model surely can allow students to do LOTS level of cognitive domain outside of the class, and develop their HOTS level inside the class. Finally, the teacher should be aware of some challenges mentioned in this study in implementing HOTS through EFL flipped speaking-classroom. Further study should include more meeting, more participating students and teachers to gain deeper understanding and more comprehensive evidence in the application of HOTS-based teaching practice in the flipped-classroom area. 


\section{ACKNOWLEDGMENTS}

Funding for this study was provided by the Indonesian Endowment Fund for Education (LPDP) scholarship.

\section{REFERENCES}

Alsowat, H. (2016). An EFL flipped classroom teaching model: Effects on English language higher-order thinking skills, student engagement and satisfaction. Journal of Education and Practice, 7(9) , 108-121.

Anderson, L. W., \& Krathwohl, D. R. (2000). A taxonomy for learning teaching and assessing: A revision of Bloom's taxonomy of educational objectives. New York: Longman.

Bergmann, J., \& Sams, A. (2012). Before you flip, consider this. Phi Delta Kappan, 94(2). doi: 10.2307/41763590

Bergmann, J., \& Sams, A. (2013). Flip your students' learning. Educational Leadership, 70(6), 16-20.

Chuang, H. H., Weng, C. Y., \& Chen, C. H. (2018). Which students benefit most from a flipped classroom approach to language learning? British Journal of Educational Technology, 49(1), 56-68. doi: $10.1111 /$ bjet. 12530

Creswell, J. W. (2012). Research design: Qualitative, quantitative, and mixed mixed methods approaches. Los Angeles: Sage.

Jacob, B., \& Matthew, A. V. (2013, June). The flipped classroom: A survey of the research. Paper presented at $120^{\text {th }}$ ASEE Annual Conference \& Exposition, Atlanta.
Lee G., \& Wallace, A. (2017). Flipped learning in the English as a foreign language classroom: Outcomes and perceptions. TESOL QUARTERLY, 52(1), 62-84. doi: 10.1002/tegs.372

Li, S., \& Suwanthep, J. (2017). Integration of flipped classroom model for EFL speaking. International Journal of Learning and Teaching, 3(2) 118-123. doi: $10.18178 / \mathrm{ijlt} .3 .2 .118-123$.

Lin, C.-J., \& Hwang, G. J. (2018). A learning analytics approach to investigating factors affecting EFL students' oral performance in a flipped classroom. Educational technology \& Society, 21(2), 205-219.

Lo, C. K., \& Hew, K. F. (2017). A critical review of flipped classroom challenges in K-12 education: Possible solutions and recommendations for future research. Research and Practice in Technology Enhanced learning, 12(4), 1-22. doi: 10.1186/s41039-016-0044-2

Quyen, T. T. T., \& Loi, V. N. (2018). Flipped model for improving students English speaking performance. Can Tho University Journal of Science, 54(2), 90-97. doi: 10.22144/ctu.jen.2018.012

Yu, Y. (2019). Problems in and solutions to oral English teaching in rura middle school - A case study in ZhaoC heng middle school. Journal of Language Teaching and Research, 10(2), 372-382. doi: 10.17750/jltr.1002.20

Yue, Z. X. (2016). Motivation in a flipped classroom, a case study of teaching oral English in a vocational college in mainland China. Sino-US English Teaching, 13(6), 460-467. doi: 10.17265/1539-8072/2016.06.004

Zainuddin, Z., Habiburrahim, H., Muluk, S., \& Keumala, C.M. (2019). How do student become self-directed learners in the EFL flipped-class pedagogy? A case study in higher education. Indonesian Journal of Applied Linguistics, 8(3), 678-690. doi: 10.17509/ijal.v8i3.15270 